\title{
O ENCARCERAMENTO FEMININO NO ESTADO DE MATO GROSSO DO SUL E A REINCIDÊNCIA CRIMINAL
}

\author{
THE INCARCERATION OF WOMEN IN THE STATE OF MATO GROSSO DO SUL AND \\ THE RECURRENT CRIMINAL BEHAVIOR
}

\author{
Lisandra Moreira Martins * \\ Isael José Santana **
}

Data de recebimento: $19 / 01 / 2015$

Data da aprovação: 10/06/2015

\section{RESUMO}

Devido à ausência de uma política efetiva de segurança pública e a necessidade de desenvolver meios para alcançá-la de forma que possa atender aos dispostos nas normas vigentes, o Direito Penal vem ganhando destaque com a inversão da ultima ratio para a prima ratio. Isso ocorre em virtude de apresentar um forte caráter opressor ao direito à liberdade, bem como ao aspecto velado de solucionador, amedrontador, passível de solucionar problemas sociais graves. A repressão representada pela situação atual do sistema carcerário e a falácia do discurso ressocializador retratam bem essa transformação/inversão. Além disso, diariamente são veiculadas notícias sobre a condição lamentável de estabelecimentos prisionais. Uma breve análise demonstra a nítida seletividade daqueles que são oprimidos frente ao desenvolvimento de processo legal, geralmente, pobres, negros, com baixa ou nenhuma escolaridade e sem

\footnotetext{
* Doutoranda em Direito Processual Penal pela Pontifícia Universidade Católica de São Paulo (PUC/SP); Bolsista CAPES; Docente do curso de Direito e da Pós-Graduação em Direitos Humanos da Universidade Estadual de Mato Grosso do Sul (UEMS); Coordenadora do Projeto de Pesquisa intitulado "A Reincidência

Penal à Luz do Processo Penal Constitucional"; Mestre em Direito pelo Centro Universitário Toledo (Araçatuba-SP). Especialista em Direito Processual: Grandes Transformações (UNISUL). E-mail: lisandra-adv@live.com

** Doutorando pela Pontifícia Universidade Católica de São Paulo/SP em Filosofia do Direito (PUC/SP). Professor dos cursos de Direito, Ciências Sociais e das especializações em Educação e em Direitos humanos da Universidade Estadual de Mato Grosso do Sul -UEMS.

Coordenador do Grupo de Pesquisa intitulado "Criminologia critica: diálogos interdisciplinares”. E-mail: leasijs@hotmail.com
} 
condições financeiras de contratar um advogado. Tal seletividade atinge não apenas os presos do sexo masculino, mas também as mulheres, mormente silenciadas nas pesquisas sobre o sistema penal. Dessa forma, o presente artigo trata do encarceramento feminino no Estado de Mato Grosso do Sul, com a análise da reincidência criminal, destacando a pesquisa realizada pela Ordem dos Advogados do Brasil do estado sobre a situação carcerária neste, onde se constata um aumento significativo do envolvimento nos crimes pelas mulheres. Utilizou-se da pesquisa bibliográfica com a análise dos dados disponibilizados a respeito, aplicando-se o método dedutivo-indutivo, a fim de retratar uma realidade ainda pouco debatida e carente de medidas emergenciais.

\section{PALAVRAS-CHAVE}

Mulheres Encarceradas - Reincidência Criminal - Seletividade.

\section{ABSTRACT}

Because of the absence of an effective public policy safety and the need to develop means to achieve it so that it can meet the willing under current legislation, the Criminal Law has been gaining momentum with the reversal of last resort to press ratio. This is due to present a strong oppressive character of the right to freedom, and the hidden aspect of solver, scary, capable of solving serious social problems. Repression represented by the current situation of the prison system and the resocializing speech fallacy well portray this transformation / inversion. In addition, daily, are conveyed news about the pitiful condition of prisons. A brief analysis demonstrates the clear selectivity of those who are oppressed against the development of legal process generally poor, black, with little or no education and without the financial means to hire a lawyer. Such selectivity affects not only the male prisoners, but also women, especially silenced in research on the criminal justice system. Thus, the present paper deals with the female incarceration in the State of Mato Grosso do Sul, with the analysis of criminal recidivism, highlighting the research conducted by the Portuguese state in Brazil Bar Association on the prison situation in this, which noted a significant increase in involvement in crimes by women. We used the literature to analyze the data available about it, applying the deductive-inductive method in order to portray a reality little debate and in need of emergency measures.

\section{KEYWORDS}

Incarcerated Women - Criminal Recidivism - Selectivity. 


\section{INTRODUÇÃO}

O modelo carcerário ideal é tema de muita discussão nas mais diversas áreas, sendo abordado nos aspectos sociológicos, psicológicos, criminológicos, dentre outros. Muito se reflete sobre os verdadeiros objetivos, finalidades mediatas e imediatas do cárcere. Conforme alerta Baratta (2013), estudos empíricos demonstram que é possível visualizar a formação de uma comunidade carcerária gerida por um modelo que se contrapõe aos desejáveis objetivos da reeducação e reinserção do condenado.

Nesse contexto, o direito penal demonstra que enraíza uma seletividade, a qual conduz uma relação de desigualdade iniciada na própria normatização dos fatos típicos, que deixa determinados comportamentos ilegais inumes ao processo de criminalização. Mencionado apontamento é bastante perceptível ao se considerar os estudos que demonstram quem são os encarcerados, geralmente pobres, negros, com pouco ou nenhum estudo, sem condições de contratar advogado, ou seja, aqueles que se encontram marginalizados socialmente.

No sistema carcerário, o que se tem hoje é a direção oposta à meta de proporcionar condições íntegras para a socialização do condenado e do interno. Nesse sentido, diversas são as pesquisas que demonstram a situação brasileira quando o assunto é cárcere.

No Estado de Mato Grosso do Sul, foi criada a Comissão Provisória do Sistema Carcerário, por determinação do Conselho Nacional da Ordem dos Advogados do Brasil, que percorreu mais de $3.500 \mathrm{~km}$ em visitas a presídios do Estado, relatando a situação deplorável do sistema prisional, comparando-o com a escravidão do nosso tempo.

A mencionada pesquisa foi concluída no final do mês de agosto de 2014 e relatou o aumento significativo da população carcerária, destacando que esta é tratada como "lixo humano", o que não pode continuar a ser admitido na prática. (fonte: http://www.oabms.org.br/upload/documento/relatorio_sistema_carcerario.pdf)

Os dados coletados na pesquisa chamam a atenção quando se analisa o aumento vultoso da população carcerária no estado de Mato Grosso do Sul. Enquanto no início do ano de 2013 o número de presos era 11.980, em janeiro de 2014 esse número passou para 12.431 presos, demonstrando uma preocupante aceleração nesse crescimento.

Tratando da criminalidade feminina, dados do Departamento Penitenciário Nacional (Depen) relatam que o aumento do encarceramento de mulheres nos últimos 12 anos foi da ordem de $256 \%$, isto é, o dobro do encarceramento masculi- 
no, que foi de $130 \%$. No Estado de Mato Grosso do Sul, a pesquisa realizada pela Comissão Temporária do Sistema Carcerário da OAB/MS demonstra um elevado número de mulheres envolvidas em crimes, sendo ainda mais preocupante os índices que apontam a prática de crimes ligados ao tráfico de drogas - 79,45\%(fonte: www. edicaoms.com.br).

Diante desse cenário é possível analisar quem são as mulheres que vêm se envolvendo cada vez mais com a prática de crimes e, a partir disso, pensar sobre o porquê dos elevados índices de reincidência. Essas mulheres, que são geralmente usadas como "mulas", carecem de ações efetivas para que não reiterem na conduta criminosa e tenham a aplicação de possíveis políticas públicas que não sejam meramente repressoras.

Assim, por meio dos índices de reincidência criminal, é possível verificar as causas e consequências desse problema, fazendo com que volvemos os olhos a essas mulheres encarceradas, tomando o processo social para além da proposta meramente punitivista ineficiente. Esse novo olhar para o processo punitivo é o que propõe o presente artigo, através de pesquisa bibliográfica em conjunto com a análise de dados oficiais.

\section{A DESUMANIZAÇÃO DA PENA NO SISTEMA CARCERÁRIO}

O desenvolvimento histórico sobre a pena demonstra que não houve, necessariamente, um processo de evolução social, mas que as nuances em torno da punição se deram para atender a uma exigência social, seja para responder um mal com um mal seja para eliminar e retirar do convívio social aquele que oferece um risco.

As mazelas oriundas da aplicação da pena privativa de liberdade, por meio do sistema penitenciário, não incomodam a todos como deveriam, mas apenas poucos daqueles que estão diretamente relacionados ao problema e aqueles que acreditam que uma mudança pautada na verdadeira 'humanização' é capaz de gerar soluções patentes para os problemas em torno da criminalidade.

Nos dizeres de Antonio Pedro Melchior e Rubens R. R. Casara (2013), a política criminal colocada em prática é puramente demonstrativa, de estabilização social da necessidade de segurança através do aumento simbólico das penas, da restrição das garantias processuais e do endurecimento do regime penitenciário

A equivocada justificativa de que o poder estatal aplica a pena com uma das finalidades de reeducar o criminoso, mostra-se cada vez mais inaceitável. Basta analisar de forma superficial o sistema carcerário, a maneira e quem este atinge. 
Iniciando pelo próprio direito penal com seu caráter fragmentário, é possível vislumbrar mecanismos seletivos desse sistema. De acordo com Alessandro Baratta (2013, p. 166): “O aprofundamento da relação entre direito penal e desigualdade conduz, em certo sentido, a inverter os termos em que esta relação aparece na superfície do fenômeno descrito".

Observa-se que as normas do direito penal se constroem e se transmitem de forma seletiva, estampando desigualdades, já que é visível que a maior parte dos que sofrem as consequências da sanção penal pertence a estratos sociais mais baixos. (BARATTA, 2013). Como destacam Casara e Melchior (2013, p. 51): "Afinal, a criminalização da pobreza e dos conflitos sociais desloca tudo o que é público para o penal.”.

Nos dizeres de Zygmunt Baunan, citado por Casara e Melchior (2013, p. 51) "a preocupação de nossos dias com a pureza do deleite pós-moderno se expressa na tendência cada vez mais acentuada a incriminar seus problemas socialmente produzidos.”. Além disso, conforme BARATTA (2013, p. 166), “a punição de certos comportamentos ilegais serve para cobrir um número mais amplo de comportamentos ilegais, que permanecem imunes ao processo de criminalização".

Interessante observar que a aplicação do direito penal leva a consequente provocação do sistema carcerário, verdadeiro produtor de desigualdades, em que há uma marginalização social, sendo que a própria origem desse sistema carcerário, aliada ao capitalismo, explica essa disparidade entre a real função do cárcere e aquela delineada na legislação.

Nesse sentido:

O nexo histórico entre cárcere e fábrica, entre introdução do sistema carcerário e transformação de uma massa indisciplinada de camponeses expulsos do campo, e separados dos próprios meios de produção, em indivíduos adaptados à disciplina da fábrica moderna, é um elemento essencial para compreender a função da instituição carcerária, que nasce em conjunto com a sociedade capitalista e acompanha a sua história.

A forte ligação entre o capitalismo e as matrizes históricas do sistema penal existe por este representar um forte mecanismo de controle social legitimado. De acordo com Vera Regina P. de Andrade (2012, p. 140),

o sistema penal replica a lógica e a função real de todo o mecanismo de controle social, que, se em nível micro implica um exercício de poder e de 
produção de subjetividades (a seleção binária entre o bem e o mal, o masculino e o feminino), em nível macro implica um exercício de poder (de homens e mulheres), reprodutor de estruturas, instituições e simbolismos. O sistema penal ocupa, assim, um importantíssimo lugar na manutenção do status quo social.

Tem-se, portanto, que o encarceramento como uma forma de humanização da pena não corresponde à realidade, pois se em um momento da história produziu indivíduos desiguais, hoje, em maior gravidade, mantém um setor de marginalizados sociais. Estes sofrem com a intervenção estigmatizante do sistema punitivo do Estado, que aplica a pena de modo a contribuir com o seu efeito marginalizador e atomizante (BARATTA, 2013).

Aliás, não é demais salientar que o sistema penal, na visão de Zaffaroni, constrói grupos humanos condicionados por meio de um processo de "matriz estereotípica" (matricería estereotípica). Esses grupos integram não só as pessoas criminalizadas, mas todos os profissionais que nele trabalham, tanto do segmento policial, penitenciário e judicial, fazendo com que haja uma reprodução do sistema penal com efeitos deteriorantes (SÁ, 2011).

Esse processo, que conduz a tais efeitos, pode ser identificado como méritos profissionais e lesiona seriamente a identidade dessas pessoas, o que se denomina de "policização" e "burocratização", problema que desqualifica uma mudança do sistema penal condizente com a reintegração social do apenado (SÁ, 2011).

Assim, o encarceramento tem demonstrado a punição de forma desumana, cruel e, sobretudo, um verdadeiro caminho para a continuidade da vida criminosa, sem quaisquer instrumentos legais aplicados de forma eficiente, com respaldo aos ditames da legislação que apregoa a humanização para a ressocialização.

\section{A REINCIDÊNCIA CRIMINAL ARRAIGADA NO PROCESSO PENAL BRASILEIRO}

$\mathrm{O}$ instituto da reincidência criminal é considerado pelo legislador como uma circunstância agravante de pena (artigo 61, inciso I, do Código Penal) e está arraigado no processo penal brasileiro durante todo o seu percurso histórico, isto é, desde o advento do Código Imperial de 1830, quando era prevista apenas a reincidência específica, ou seja, quando se agrava a pena daquele que havia recaído em delito da mesma natureza.

O Código Penal Republicano de 1890 também fez referência à reincidên- 
cia, conceituando a reincidência específica. Já o Código Penal de 1940 a manteve e distinguiu de forma expressa as espécies, representando um marco na distinção das modalidades específica e genérica (ALMEIDA, 2012).

$\mathrm{O}$ artigo 63 do Código Penal vigente conceitua a reincidência criminal como sendo a prática pelo agente de novo crime da mesma natureza ou não, após o trânsito em julgado de sentença condenatória exarada no Brasil ou exterior. Além dessa conceituação, a reincidência criminal gera várias consequências gravosas ao processado ou condenado, pela justificativa de ser necessário um tratamento mais rígido àquele que reitera na prática criminosa após uma condenação.

No transcorrer do processo, diversos são os impedimentos, aumento de prazos ou maior grau de dificuldade para conquistar benefícios, tais como impedimento à concessão da suspensão condicional da execução da pena (art. $77 \mathrm{CP}$ ), aumento do prazo do cumprimento da pena para a obtenção do livramento condicional (art. 83, inciso II, CP), aumento do prazo da pretensão executória (art. 110, caput, CP), interrupção da prescrição (art. 117, inciso VI, CP) e impedimento de algumas causas de diminuição de pena (arts. $155, \S 1^{\circ}, 170$ e $\left.171, \S 1^{\circ}, \mathrm{CP}\right)$, sendo circunstância preponderante quando em concurso de agravantes (art. 67, caput).

Além do Código Penal, leis específicas também tratam da reincidência, a exemplo da Lei Ambiental (Lei $n^{\circ}$ 9.605/98 - artigo 15), Lei de Drogas (Lei ${ }^{\circ}$ 11.343/06 - artigo 44, parágrafo único) e Lei dos Crimes Hediondos (Lei no ${ }^{8072}$ ).

Apesar de ter sido considerado um instrumento de política criminal aplicado àquele que volta a praticar conduta delituosa, merecedor, portanto, de uma pena mais grave, e, ainda, ter sido considerado pelo Supremo Tribunal Federal constitucional (RE 453.000/RS), há de salientar que esse arcaico instituto nada mais reflete que a falha do caráter ressocializador e preventivo da punição, sobretudo, do encarceramento.

Sem adentrar a discussão sobre os argumentos das correntes doutrinárias e jurisprudenciais em defesa da constitucionalidade e da contrária, o fato é que a partir da reincidência criminal é possível extrair o caminhar do sistema penal e de seus meios de ressocialização.

Por óbvio, não é possível deixar de mencionar o reflexo da seletividade ao se analisar a reincidência, pois até mesmo este instituto possui na construção histórica a finalidade de segregação, seletividade e marginalização de uma classe social.

Na visão crítica do professor e jurista Lenio Streck (2014, n.p):

Já disse isso várias vezes (afinal, sofro de LEER - Lesão por Esforço Epistêmico Repetitivo): o Código Criminal de 1830 foi feito para pegar escravos, o de 1890, para pegar ex-escravos e seus filhos, e o de 1940 para 
proteger nitidamente a propriedade privada contra os ataques da patuleia, a ponto de dobrar a pena no furto nos casos de escalada, chave falsa, etc. Elementar isso, pois não?

Dessa forma, tem-se que o instituto da reincidência criminal está inserido no direito como uma cultura de punição mais gravosa, atribuindo-se exclusivamente ao apenado a responsabilidade pelo reiterado descumprimento da lei.

De nada adiantam inúmeras leis penais com a justificativa de controle da criminalidade, sem o investimento no sistema penal em prol de uma nova formatação que, de fato, torne-o compatível com os objetivos da Lei de Execução Penal.

De acordo com Vanessa Maria Feletti (2014, p. 56): "Não obstante as expectativas teóricas de declínio nos índices de criminalidade, o que se viu em ambos os lados do atlântico foi o aumento do número de crimes e do encarceramento, incluindo de reincidentes".

Esquece-se, ainda, de sobrelevar a falha estatal na pretendida ressocialização, o que tem se tornado um problema social cada vez mais grave, considerando que $80 \%$ dos egressos são reincidentes, o que foi destacado no voto do Ministro Gilmar Mendes no julgamento do RE 453.000/RS. Com isso, todo o processo penal é deturpado, deixando de atender às finalidades sociais e políticas (LOPES Jr, 2006).

Dessa forma, o processo penal se desenvolve sem atentar aos preceitos constitucionais, "fazendo vítimas cotidianamente. E quem mais sofre são naturalmente os componentes do andar de baixo da sociedade" (STRECK, 2014).

Não é demais reforçar que, para aqueles que defendem o discurso autoritário, tornam-se óbices à eficiência punitivistas as garantias que constituem o processo penal democrático. Por isso, para estes, devem ser relativizadas, o que ocasiona a legitimidade do gênero de violência.

Assim sendo, por meio da análise do instituto da reincidência criminal e de seus índices é possível desdobrar diversos problemas que evidenciam a crise no sistema penal. Há que se perder a fantasia "de que uma produção legislativa que amplia o poder penal representa um avanço, uma "superação" da crise da segurança pública, rumo à obtenção dos fins prestigiados pelo discurso oficial (CASARA; MELCHIOR, 2013, p. 39).

Disso, extrai-se que está longe da reincidência criminal funcionar como um meio de redução da criminalidade, por isso se faz necessário retratar as diversas falhas existentes desde a construção do sistema penal, refletindo no sistema penitenciário, com o elevado número de reincidentes. 


\section{O encarceramento feminino no Estado de Mato Grosso do Sul}

Sabendo que a grande maioria dos encarcerados é sexo masculino, muitos debates jurídicos em torno dos problemas gerados pelo sistema prisional não focam nos problemas também vivenciados pelas mulheres apenadas.

Quando se menciona o sistema prisional, a imagem primeira é da rebelião em presídios masculinos, no entanto, a restrição da liberdade via processo penal não difere os gêneros, mas nos remete à reflexão do momento histórico e do crescimento, ou suposto, entre as mulheres.

O processo social de exclusão das mulheres não é apenas direcionado nos direitos a acessos dos espaços públicos, pois a invisibilidade da mulher ocorre no mais opressor dos sistemas, que é o do encarceramento. Na esfera da criminalidade, embora silenciosamente, podemos apontar dados oficiais que demonstram um crescimento de $256 \%$ (duzentos e cinquenta e seis) por cento nesse processo de reclusão.

Consoante Vera Regina P. de Andrade:

E nada simboliza melhor a seletividade do que a clientela da prisão, ao revelar que a construção (instrumental e simbólica) da criminalidade - a criminalização - incide seletiva e de modo estigmatizante sobre a pobreza e a exclusão social, majoritariamente de cor não branca e masculina, e apenas residualmente (embora de forme crescente) feminina.143: (...) podemos constatar que há no Brasil uma aproximação entre os dados da criminalização da pobreza (em torno de $95 \%$ ) e os dados da criminalização masculina (em torno de 96\%), contra aproximadamente $4 \%$ de criminalização feminina, entretanto, progressivamente ascendente. (Grifo nosso). (2012, p.137/138)

A violência nos remete à suposta força física do gênero masculino, embora não seja exatamente ela que seja capaz da produção da criminalidade, uma vez que diversos tipos de crimes, como o tráfico de drogas, independem de força, por isso associá-la ao homem seria um equívoco. No entanto, se o crescimento foi quase o dobro do encarceramento masculino, a representação de mulheres encarceradas ainda é de $7 \%$ (sete) por cento.

O processo penal tem por escopo a defesa da pessoa acusada sendo, portanto, meio de defesa, mas sabemos que o mero dispositivo não pode explicar o aumento de encarceramento, contudo, pode explicar uma mudança na forma de apenamento das mulheres. Há uma relação direta de aplicadores do direito, em especial Ministério Pú- 
blico e juízes que apontam para uma igualdade de potencialidades criminosas.

O que se pode apontar é que mulheres são tratadas igualmente na esfera do processo e esquecidas nos espaços do sistema penitenciário. Não se poderia esperar que no país mais encarcerador do mundo fosse diferente para com o gênero feminino. Cabe-nos perguntar, desse modo, de que forma o processo penal trata a mulher na sua esfera de persecução penal e execução?

Efetivamente não há prisões boas, mas elas podem ser piores, não ao acaso, as lágrimas dos magistrados dizem ter vergonha de fazer parte do processo penal, sobretudo pela impossibilidade de se ver qualquer chance de recuperação advinda das prisões. Nesse sentido, a mulher encontra no processo, e mesmo no sistema condições diferentes, caracterizando uma extrema seletividade e maior rigor na aplicação de penas.

No departamento nacional penitenciário, o último censo apontou números de exclusão de pobre, negros, analfabetos, assim como já nos alertava em décadas passadas Neder afirma que:

As prisões (em todo o país) escancararam uma podridão que ressalta a arrogância e o descaso das elites e dos governantes em relação aos direitos (em geral), mas, sobretudo, aos direitos humanos das classes subalternas. $\mathrm{O}$ esgarçamento das relações sociais em situações de crise econômica, social, política e moral como a vivida presentemente tende a fazer emergir esta podridão, como o fez o episódio da Bastilha que detonou o processo revolucionário francês em 1789. (1994, p. 12)

O processo de exclusão social não pode ser meramente ao acaso, não pode ser apenas a aplicação do direito posto e, especialmente, a sanha contra aqueles que não têm(aqui o não ter é amplo, pois não o têm desde o capital aos direitos, que mormente são ou estão ao alcance dos que têm).

A forma pontual aponta a relação excludente em Wacquant (2001, p. 10):

Uma última razão, de simples bom senso, milita contra um recurso acrescido ao sistema carcerário para conter a escalada da miséria e dos distúrbios urbanos no Brasil. É o estado apavorante das prisões do país, que se parecem mais com campos de concentração para pobres, ou com empresas públicas de depósito industrial dos dejetos sociais, do que com instituições judiciárias servindo para alguma função penalógica - dissuasão, neutralização ou reinserção. 
Para exemplificar, em 1993, o censo penitenciário apontava um universo de 126.152 presos, pouco mais de 20 se passaram anos e temos, agora, 568 mil presos. Na época, tínhamos $2 / 3$ de declarados negros ou mulatos, $76 \%$ analfabetos ou semianalfabetos, $98 \%$ sem condições de contratar serviços de advocacia e nada mais, nada menos que 95\% na faixa da pobreza absoluta (MINHOTO, 2000, p. 179-180).

Diferente não pensa Neder (1994, p. 12): "Considerando-se que a seletividade do sistema penal brasileiro atinge os pobres, os negros e os nordestinos (migrantes depauperados), na sua maioria jovens e do sexo masculino, pode-se caracterizar esta prática de extermínio humano como genocida".

A questão do uso de entorpecentes influencia de forma inegável nos índices de criminalidade. Há ações que visam à intervenção nos estratos sociais em que estão, de alguma forma, sofrendo o desequilíbrio da concessão dos direitos elementares. Entre eles, há de se considerar que a questão da criminalidade, mais social ou, de forma ampla, um problema de políticas públicas, aqui entendidas como o conjunto e não somente a aplicação ineficiente de um Estado repressor por meio da segurança pública, quiçá pudesse ser solucionada por meio da pena, desejada e enaltecida por desconhecimento ou incompetência estatal.

A violência gerada em razão da questão do uso de substâncias ilícitas é de difícil combate, pois não se trata, como mencionado, de questão criminal, mas social. Outros fatores repercutem na esfera criminal, tais como furto, roubo e receptação, e não podemos afastar fatores como o "sustento" do vício como forma de arregimentação de mulheres para o tráfico.

O Estado de Mato Grosso do Sul encontra-se geograficamente localizado nas fronteiras (Paraguai e Bolívia), mas deve ser considerado em Foz do Iguaçu o acesso à Argentina. Pode-se, ainda, dizer que há uma porta de acesso para outros países como a Venezuela, conforme matéria publicada no site da Câmara dos Deputados (fonte: http://www2.camara.gov.br), e pode-se, também, observar que o país vizinho Paraguai é atualmente a maior preocupação da Polícia Federal, já que o referido país é o segundo maior produtor de maconha do mundo.

É possível dizer que a questão do uso de entorpecentes é democrática, mas não a punição. Entre aqueles que se submetem ao poder coercitivo do Estado, há o que se pode denominar ínfimo de pessoas que irão se submeter ao seu poder coercitivo, sendo-lhes impostos penas de modo desmedido. Assim, tal seleção penal pune aqueles de baixo poder econômico, com todo um estigma social como se fossem de fato os responsáveis pelas mazelas sociais.

O traficante tem, portanto, de acordo com a criminóloga Vera Malaguti 
Batista, um rosto já definido. O bandido se forma na figura do(a) jovem negro(a), morador(a) de periferias (apud ZACCONE, p. 21), pune-se, pois, por condição social por meio de um julgamento em razão do estrato de que a pessoa advém; é o que se denomina labelling appoach ${ }^{1}$.

As teorias criminológicas são desenvolvidas para analisar as causas da criminalidade e as possíveis soluções. Dentre estas, destaca-se a teoria do etiquetamento, que possui como tese central a disposição de que "a criminalidade não é a qualidade de uma determinada conduta, mas o resultado de um processo através do qual se atribui dita qualidade, quer dizer, de um processo de estigmatização" (CONDE; HASSEMER, p. 111).

A teoria do etiquetamento demonstra que ainda há um processo de seleção à criminalidade, estigmatizando uma classe de pessoas menos favorecidas, o que remete não apenas à reflexão da desigual aplicação do Direito Penal, mas, sobretudo, ao reconhecimento de que muitos criminosos que causam prejuízo não a uma, porém a milhares de pessoas agem de forma acobertada pelos interesses econômico e político, permanecendo na cifra da impunidade, com desvencilho de todos os preceitos constitucionais voltados à concretude de um Estado realmente democrático e com a efetivação dos mais diversos direitos fundamentais.

As mulheres vêm tomando seu espaço na sociedade, ainda que lentamente, há o empoderamento da mulher, e tal se dá em todos os campos. Desde a ação em Seneca Falls(1848), Nova York, ocorre a convenção dos direitos femininos. Neste mesmo Estado, em 1857, no dia 08 de março, a busca pela redução da jornada de trabalho, bem como o direito à licença maternidade, resultou na pressão policial que ceifou a vida de 129 mulheres, origem do dia internacional da mulher, que denota a árdua campanha das mulheres em prol de direitos.

Friedrich Engels, em nome da luta pela emancipação e consciência da mulher, na obra "A origem da família, da propriedade privada e do Estado", preceitua que:

[...] emancipação da mulher e sua equiparação ao homem são e continuarão sendo impossíveis, enquanto ela permanecer excluída do trabalho produtivo social e confinada ao trabalho doméstico, que é um trabalho privado. A emancipação da mulher só se torna possível quando ela pode participar em grande escala, em escala social, da produção, e quando o trabalho doméstico the toma apenas um tempo insignificante (ENGELS, 1974, p. 182).

${ }^{1}$ Teoria que trata da criminalidade a partir da construção do conceito de forma mais ampla, entre agente e órgãos oficiais de controle, assim a teoria estuda a função constitutiva da infração ao bem jurídico-penal. 
As grandes lutas, como a "queima dos sutiãs", embora nenhum tenha sido de fato queimado, são símbolos da contestação opressiva, da luta pelo espaço social que se deu ao longo dos anos, sendo menção histórica para situar uma busca ainda necessária dos espaços gerais e de igualdade.

A propositura vem para que possamos entender que ainda as mulheres ocupam cargos considerados de menor importância, ou mesmo subalternos nos espaços de trabalho, quase sempre precarizados.

É nesse sentido que as mulheres, no tráfico de entorpecentes, ocupam a cadeia do trabalho mal pago e mais perigoso que é o transporte de drogas, em que são denominadas de forma animalesca, ou seja, pela incapacidade de pensar e apenas usar o corpo.

Tais transportadoras de drogas são denominadas "mulas", ou seja, o sujeito que carrega a carga. As que carregam pequenas quantidades, mas de forma frequente, são denominadas "formigas", pela constância no ir e vir nessa atividade, normalmente, o tráfico internacional.

Uma possibilidade seria a ideia de que a mulher levantasse menores suspeitas, aliada ao fato de que a norma veda, a priori, revistas por policiais do sexo masculino, sabendo que a corporação da polícia militar tem em seu efetivo um grande número de policiais deste sexo. Ainda, a mulher, conforme uma cultura machista seria menos propensa ao crime, e mesmo os policiais teriam para com estas, maior parcimônia.

Contudo, não é o que vem ocorrendo, principalmente pela gravidade da punição que se gerou em torno do tráfico de drogas e o aumento deste nos presídios. Vale mencionar que o crime de tráfico de drogas está previsto em legislação especial (Lei $n^{\circ} 11.343 / 2006$, com alterações dadas pela Lei 12.961/2014), o que demonstra o expansionismo do direito penal, conforme o espanhol Jesús-Maria Silva Sanches, em virtude de uma inflação legislativa sempre de caráter de reprimenda sem, no entanto, ter qualquer eficácia na esfera da eficiência desejada, mas atende a uma cultura punitivista reinante.

Dessa feita, a previsão do enquadramento dessas mulheres, que são mais coisificadas no processo da atividade, pois descartáveis aos traficantes e ao Estado ausente em suas necessidades fundamentais, está no artigo 33 da referida legislação, com pena agravada na nova lei que tem como base 05 anos, o que, per si, impede a substituição da pena por medida alternativa, e máxima de 15 anos.

Fosse apenas à expressão da norma, poderíamos dizer que a primariedade poderia impor reduções, mas a realidade encontrada é a existência da previsão do o 
crime no artigo 33 agregado aos demais, como 40, inciso V (tráfico entre estados, que prevê aumento da pena de $1 / 6$ a 2/3), podendo ainda somar-se a associação criminosa, conforme os fatos.

Todavia, decisões como as proferidas no Estado de Mato Grosso do Sul têm entendido que é aplicável a pena alternativa, afastando a hediondez prevista na Lei $\mathrm{n}^{\mathrm{o}}$ 8.072/90 - "Art. $2^{\circ}$ Os crimes hediondos, a prática da tortura, o tráfico ilícito de entorpecentes e drogas afins (...)" (grifo nosso), aplicando a previsão legal da individualização da pena e demonstrando que o grande número das mulheres encarceradas é de primárias de bons antecedentes, que poderiam ter o benefício das penas alternativas, inclusive por saber que o cárcere jamais recuperou qualquer cidadão, conforme transcreve-se:

EMENTA - AGRAVOREGIMENTAL EM AGRAVO EM EXECUÇÃO PENAL - RECURSOMINISTERIAL - TRÁFICO DE DROGAS -CONDUTAPRIVILEGIADA - ART.33, § 4. ${ }^{\circ}$, LEI 11.343/06 - AFASTAMENTO DA HEDIONDEZ -INEXISTÊNCIADE PREVISÃO LEGAL - ROLTAXATIVO - RECURSO IMPROVIDO.

Em se tratando de rol taxativo, por inexistência de previsão legal expressa, o reconhecimento da conduta privilegiada do tráfico de drogas (art. 33, § 4. ${ }^{\circ}$, da Lei n. 11.343/06) afasta a hediondez do crime. (Agravo Regimental em Agravo Criminal - N. 2009.033667-2/0001-00 - Ponta Porã. Relator Exmo. Sr. Des. Claudionor Miguel Abss Duarte. Segunda Turma Criminal. Julgado em 18.1.2010).

AGRAVO CRIMINAL - RECURSO DEFENSIVO - TRÁFICO PRIVILEGIADO - HEDIONDEZ AFASTADA - CONCESSÃO DA PROGRESSÃO PRISIONAL E DO LIVRAMENTO CONDICIONAL NOS PRAZOS PREVISTOS PARA O CRIME COMUM - RECURSO PROVIDO.

Considerando que o crime de tráfico privilegiado não está elencado no rol dos hediondos e assemelhados, impõe-se a concessão da progressão prisional e do livramento condicional nos prazos previstos para o crime comum. (Agravo Criminal - N. 2011.003408-1/0000-00 - Campo Grande - Relator Des. Manoel Mendes Carli - Segunda Turma Criminal, 28.2.2011).

Insta salientar que, no levantamento de dados do Relatório do Sistema Carcerário do Mato Grosso do Sul, foi constatada superlotação no regime fechado no tocante à população feminina, com a ausência de 135 vagas em Campo Grande e 186 
nas demais cidades do estado, com um alto índice de envolvimento das mulheres, como já mencionado, nos crimes previstos na Lei de Drogas (79.45\%), com 11,24\% nos crimes contra o patrimônio; $3,84 \%$ nos crimes contra a pessoa; $3,52 \%$ em outros crimes e 1,95\% nos crimes contra a dignidade sexual. (Fonte: http://www.oabms.org. br/upload/documento/relatorio_sistema_carcerario.pdf - p. 13).

Assim sendo, diante de toda a problemática enfrentada, é possível afirmar que, à luz da reincidência criminal voltada à análise do crescimento do encarceramento das mulheres, o tratamento diferenciado desde a formatação do direito penal e do sistema prisional continuam marcando a história como um processo de seletividade e segregação de uma camada populacional determinada, sem medir as consequências do rigorismo exacerbado, da política criminal populista e da ineficácia da estrutura ora construída.

Mencionada história foi bem retratada por Dráuzio Varella no documentário "Quebrando o tabu" (ANDRADE, 2011, n.p.):

Olha, na penitenciária feminina a coisa mais pura que eu vejo são essas meninas pegas levando droga para dentro das cadeias. O que acontece com elas? Elas têm um marido, um namorado preso. São iludidas por eles que vão morrer, receber uma droga para pagar uma dívida ou outras que fazem isso mesmo para ganhar dinheiro. Colocam a cocaína num saco plástico e colocam a cocaína dentro da vagina, quando passam pela revista na porta de cadeia às vezes a funcionária desconfia, manda agachar, a tossir etc. Pega a droga. Essa menina sai da cadeia e vai direto para a delegacia, da delegacia vai para a penitenciária do estado. E muitas vezes o juiz dá 04 anos de cadeia, às vezes ela nem voltou para a casa depois que saiu para fazer a visita na cadeia, deixou o filho de 09 anos cuidando dos 03 mais novos, não voltou e o que acontece com essas crianças? Uma prima pega um, a vizinha pega outro, ou ficam sob a custódia do Estado. Qual o futuro dessas crianças? Porque isso é uma gota d'água no oceano do tráfico de drogas e você destrói uma família e cria futuros marginais, deixando essas crianças sem apoio materno.

Com a formação de um círculo vicioso de quem são os criminosos, voltando-se a atenção especial às mulheres, a continuidade desse sistema de segregação não será obstada se persistirem a falta de análise crítica à situação atual e o pouco desenvolvimento, quiçá nenhum, de medidas verdadeiramente eficientes e com caráter de humanismo, capazes de impedir que o quadro acima relatado continue fazendo parte da história do processo brasileiro. 


\section{CONCLUSÃO}

A questão da invisibilidade social da mulher merece uma discussão aprofundada, sobretudo para buscar mapear as relações entre ela e o cárcere feminino, exigindo-se um estudo apartado em torno dos problemas enfrentados por essas quando do cumprimento da sanção penal.

As questões sociais excludentes são meramente consideradas como mazelas do sistema carcerário ineficiente e ineficaz, que atinge quase que exclusivamente uma classe sempre marginalizada, que em muitas vezes lhes restam poucas ou nenhuma oportunidade das promessas da modernidade.

Após o cárcere, no processo penal, em sua amplitude de revestir-se em instrumento de defesa da cidadania e garantia da segurança jurídica, que por vezes só aparece quando o Estado tem por escopo a punibilidade, encontramos a determinada reincidência que tem, por força de decisão da Corte maior, a constitucionalidade, para sacramentar o fracasso dos objetivos da segregação.

Tem-se uma política criminal do incremento legislativo seguindo em contramão dos preceitos constitucionais que devem embasar o processo penal democrático de direito, que garanta ao processado e, consequentemente, apenado direitos fundamentais para a efetiva ressocialização ou reintegração social.

Os avanços jurídicos de concessão de progressão e afastamento da reprimenda hedionda não são o bastante para tratar questões de tamanha profundidade das mulheres encarceradas. Não se nega o tímido avanço, mas a ausência de políticas criminais que possam individualizar a pena e mesmo a análise da reincidência frente ao fato em si.

Dessa forma, após a constatação dos dados lançados pela Comissão Temporária do Sistema Carcerário da $\mathrm{OAB} / \mathrm{MS}$, concluída no final do mês de agosto de 2014, é possível verificar que o aumento do envolvimento das mulheres no mundo do crime, especialmente, no crime de tráfico de drogas confirma a seletividade retratada.

A partir do instituto da reincidência criminal, as finalidades justificadoras do cárcere demonstram-se inócuas, devido a pouca ou nenhuma efetividade. Assim, conclui-se que as mulheres encarceradas são aquelas excluídas, segregadas, que sofrem com o processo penal fragmentador, elitista e legalista, havendo a necessidade de amadurecimento desse problema tanto em âmbito acadêmico, quanto na prática quando da aplicação de uma pena, que pode refletir uma dupla ou exacerbada punição, demandando emergentes soluções. 


\section{REFERÊNCIAS}

ALMEIDA, Débora de Souza de. Reincidência criminal: reflexões dogmáticas e criminológicas. Curitiba: Juruá, 2012.

ANDRADE, Vera Regina Pereira de. Pelas mãos da criminologia: o controle penal para além da (des)ilusão. Editora Renavan: Rio de Janeiro, 2012.

ANDRADE, Jenis. Scanner Corporal. Disponível em: <http://jenisandrade. blogspot. com/2011/02/scanner-corporal_13.html> Acesso em: 02 ago. 2014.

BARATTA, Alessandro. Criminologia Crítica e Crítica do Direito Penal: introdução à sociologia do direito penal. Tradução Juarez Cirino dos Santos, $6^{\mathrm{a}}$ ed.. Editora Renavan: Rio de Janeiro, 2013.

BRASIL. Código Penal. Decreto-Lei n. 2.848 de 7 de dezembro de 1940. Disponível em < http:// www.planalto.gov.br/ccivil_03/decreto-lei/del2848compilado.htm> Acesso em 09 out 2014.

CASARA, Rubens R. R; MELCHIOR, Antonio Pedro. Teoria do processo penal brasileiro: dogmática e crítica. Vol. I: conceitos fundamentais, Rio de Janeiro: Lumen Juris, 2013.

CONDE, Francisco Muñoz e HASSEMER, Winfried. Introdução à Criminologia, $2^{\mathrm{a}}$ tiragem, Editora Lumen Juris, Rio de Janeiro: 2011.

Edições MS. Disponível em:

$<$ http://www.edicaoms.com.br/noticias/136886, Situacao+carceraria+de+MS+ainda+e+alarmante,+aponta+OABMS.html> Acesso em 30 ago. 2014.

ENGELS, Friedrich. A origem da família, da propriedade privada e do Estado. Rio de Janeiro: Editora Civilização Brasileira, 1974.

MORAES, Alexandre Rocha Almeida de. Direito Penal do Inimigo. A Terceira Velocidade do Direito Penal. Curitiba: Juruá, 2009.

FELETTI, Vanessa Maria. Vende-se segurança: a relação entre o controle penal da força de trabalho e a transformação do direito social à segurança em mercadoria. 1. ed., Rio de Janeiro: Renavan, 2014.

FERNANDES, Antônio Scarance. Processo Penal Constitucional. $4^{\mathrm{a}}$ Ed. São Paulo: Revista dos Tribunais, 2005. 
FRANCO, Alberto Silva. Reincidência: um caso de não-recepção pela Constituição Federal; Boletim IBCCRIM. no 209 . Abr. 2010. Disponível em <http://www.ibccrim.org.br/> Acesso em 08 out 2014.

LOPES Jr., Aury. Introdução Crítica ao Processo Penal: fundamentos da instrumentalidade constitucional. $4^{a}$ edição, rev. atual. eampl.. Rio de Janeiro: Editora LumenJuis, 2006.

MINHOTO, Laurindo Dias. Privatização de presídios e criminalidade: a gestão da violência no capitalismo global. São Paulo: Max Limonad, 2000.

NEDER, Gizlene. Violência e cidadania. Porto Alegre: Sergio Antonio Fabris, 1994.

Relatório do Sistema Carcerário do Mato Grosso do Sul - 2014. Disponível em < http://www. oabms.org.br/upload/documento/relatorio_sistema_carcerario.pdf $>$ Acesso em 15dez 2014.

SÁ, Alvino Augusto de. Criminologia clínica e execução penal: proposta de um de modelo de terceira geração. São Paulo: Revista dos Tribunais, 2011.

SILVA SANCHEZ, Jesús-Maria. A expansão do direito penal: aspectos da política criminal nas sociedades pós-industriais. 3. ed. São Paulo: Editora Revista dos Tribunais, 2013.

Supremo Tribunal Federal. Disponível em < http://www.stf.jus.br/portal/cms/verNoticiaDetalhe.asp?idConteudo=235084 $>$ Acesso em 05out 2014 .

STRECK, Lenio. Direito penal do fato ou do autor? A insignificância e a reincidência. Disponível em < http://www.conjur.com.br/2014-out-09/senso-incomum-direito-penal-fatoou-autor-insignificancia-reincidencia> Acesso em 09 out 2014.

ZACCONE, Orlando. ACIONISTAS DO NADA: quem são os traficantes de drogas. $2^{\mathrm{a}}$ Edição. Editora Revan. Rio de Janeiro, 2008.

WACQUANT, Loïc. As prisões da miséria. Rio de Janeiro: Jorge Zahar, 2001. 